\title{
Empiric Treatment of Acute Meningitis Syndrome in a Resource- Limited Setting: Clinical Outcomes and Predictors of Survival or Death
}

\author{
Birkneh Tilahun Tadesse ${ }^{1}$, Byron Alexander Foster ${ }^{2}$, Mulugeta Sitot Shibeshi ${ }^{1}$, \\ HenokTadele Dangiso ${ }^{1}$
}

\section{OPEN ACCESS}

Citation: Birkneh Tilahun Tadesse, Byron Alexander Foster, Mulugeta Sitot Shibeshi, HenokTadele Dangiso. Empiric Treatment of Acute Meningitis Syndrome in a Resource-Limited Setting: Clinical Outcomes and Predictors of Survival or Death. Ethiop J Health Sci.2017;27(6):581.

doi:http://dx.doi.org/10.4314/ejhs.v27i6.3

Received: June 11, 2017

Accepted: June 13, 2017

Published: November 1, 2017

Copyright: @ 2017 Birkneh T. et al. This is an open access article distributed under the terms of the Creative Commons Attribution License, which permits unrestricted use, distribution, and reproduction in any medium, provided the original author and source are credited. Funding: Nil

Competing Interests: The authors declare that this manuscript was approved by all authors in its current form and that no competing interest exists.

Affiliation and Correspondence:

${ }^{1}$ Department of Child Health, Hawassa University College of Health Sciences, Hawassa, Ethiopia

${ }^{2}$ Department of Pediatrics, Oregon Health \& Science University, Oregon ,USA

*Email: fosterb@ohsu.edu

\section{ABSTRACT}

BACKGROUND: Bacterial meningitis is a significant cause of morbidity and mortality in the developing world. However, limited research has focused on the diagnosis and management of meningitis in resource-limited settings.

METHODS: We designed a prospective case series of children admitted to a large, academic referral hospital with acute meningitis syndrome. Data were collected on age, time of presentation, prior antibiotics, cerebrospinal fluid (CSF) parameters, antibiotic and steroid prescription, and clinical outcome.

RESULTS: Data on 99 patients were collected and analyzed. Most of the patients were males, $n=69(70 \%)$, and were from a rural area, $n=83$ (84\%). Incomplete vaccination was common, $n=36$ (36\%) and many have evidence of malnutrition, $n=25$ (38\%). Most patients, $n=64$ (72\%), had received antibiotics prior to admission with a mean duration of symptoms of 4.9 days prior to admission. The CSF white blood cell (WBC) count was higher in those who had not received prior antibiotics though it was elevated in both groups. The CSF WBC count was not associated with survival; malnutrition and length of symptoms prior to admission were both associated with decreased survival.

CONCLUSIONS: While use of antibiotics prior to obtaining CSF in patients with acute meningitis syndrome may decrease their CSF WBC count, it is not clinically significant. Many patients had a significant delay in presentation that had an effect on survival, This is a potentially modifiable risk factor despite the resourcelimited setting.

KEYWORDS: bacterial meningitis, children, antibiotics, glucocorticoids
INTRODUCTION

DOI: http://dx.doi.org/10.4314/ejhs.v27i6.3 
Bacterial meningitis is a significant source of mortality and morbidity, particularly in the developing world (1-3). The incidence in the United States is less than 1 per 100,000 persons whereas in much of sub-Saharan Africa, it is 1025 per 100,000 persons (4). A recent study from Canada found a $8.4 \%$ mortality rate and $18 \%$ complication rate amongst patients with meningococcal disease, one of the major causes of meningitis (5). In resource-limited settings, the mortality is approximately one third of patients when examining all etiologies, with higher mortality associated with either pneumococcal disease or Haemophilus influenzae type b (Hib) meningitis (1). Given the morbidity, treatment decisions must be made in a timely manner before any microbiologic confirmation can be done. One of the major challenges faced by clinicians where the worldwide preponderance of disease occurs is the interpretation of cerebrospinal fluid (CSF) cell counts in the absence of microbiologic culture, antigen testing or viral testing, which is the case in much of the developing world $(6,7)$.

Theoretically, clinical prediction rules or scoring systems could help stratify patients into high risk and low risk for the diagnosis of bacterial meningitis. However, the literature discussing such clinical scoring systems use Western populations with significantly different pathogen and immunization patterns from other parts of the world $(8,9)$. Another significant challenge is the evaluation of CSF in the context of prior antibiotic exposure, with most of the evidence informing this evaluation coming from a clinical and epidemiologically population distinct from sub-Saharan Africa with different immunization regimens and disease patterns $(10,11)$.

In this study, we sought to address three questions to help clarify the issues identified above:

1. What is the pattern of CSF pleocytosis among patients treated with antibiotics prior to lumbar puncture?

2. What is the relationship between level of CSF pleocytosis and outcome in children clinically diagnosed to have acute meningitis?
3. What is the relative effectiveness of commonly used antibiotic regimens in acute meningitis syndrome?

\section{METHODS}

Study design and data collection: We designed a prospective case series of patients presenting with acute meningitis syndrome. Patient data were collected on the pediatric ward of Hawassa University Referral Hospital in Hawassa, Ethiopia, between January 2013 and February 2014. Patients with clinical suspicion for acute meningitis were entered into the database sequentially as they were admitted, with the World Health Organization (WHO) clinical definition of meningitis used: sudden onset of fever with one or more typical clinical features (seizures other than febrile seizures, neck stiffness, altered consciousness, irritability, other meningeal signs, petechial or purpuric rash). The inclusion criterion was completion of a diagnostic lumbar puncture. As per the national guidelines (12) for Ethiopia, if patients presents with acute meningitis syndrome, they should be started on high dose crystalline penicillin and chloramphenicol. If patients have taken antibiotics before they arrive to the hospital, ceftriaxone is started empirically (12). If they present to a health center prior to transfer to a larger tertiary care hospital or teaching hospital and a serious febrile illness is recognized by the health staff, they should receive a dose of ampicillin and gentamicin prior to transfer. Patients who were too unstable for a lumbar puncture or whose malaria smear was positive were excluded from the study. Missing values were addressed using a chart review when possible.

We prospectively collected data on vaccination status as per parental report, demographic information of home town, malnourishment status, HIV status, known tuberculosis contacts, receipt of antibiotics prior to admission and all prescribed antibiotics during the hospitalization. The WHO guidelines for malnourishment assessment were followed for all admitted patients (13). Mild malnutrition is

DOI: http://dx.doi.org/10.4314/ejhs.v27i6.3 
defined as a weight-for-height between -1 and -2 z-scores below the median of WHO child growth standards, and moderate malnutrition is defined as a weight-for-height between -3 and -2 z-scores below the median. Severe malnutrition is diagnosed with a weight for height less than $-3 \mathrm{z}-$ scores of the median, mean upper arm circumference $<11.5 \mathrm{~mm}$, and presence of edema. For our antibiotic variable, any combination of antibiotics the patients received was used to group them, whether sequentially or together, during the same hospitalization.

Ethics: This study was approved by Hawassa University Institutional Review Board. A waiver of consent was obtained from the Institutional Review Board as patients did not provide informed consent as all data were de-identified.

Statistics and power: We estimated a target sample size of 100 using a power calculation for the analysis of antibiotic pre-treatment versus none. Using historical data from prior work and an estimated CSF white blood cell (WBC) count of 2,000 per $\mathrm{mm}^{3}$ in untreated cases and 1,000 per $\mathrm{mm}^{3}$ in patients pre-treated with antibiotics and a standard deviation of 2,000 per $\mathrm{mm}^{3}$, a sample size of 100 would have $94 \%$ power to detect a difference. For detecting a smaller difference of 2,000 per $\mathrm{mm}^{3}$ in untreated cases versus 1,500 per $\mathrm{mm}^{3}$ in pre-treated cases, a sample size of 100 would only have $43 \%$ power.

We used both parametric and non-parametric descriptive statistics for the analyses. Normality was assessed both qualitatively and using ShapiroWilk tests. A logistic regression model with the outcome of survival was completed using a forward step-wise model building approach. SPSS version 19.0 (IBM, USA) was used for all analyses.

\section{RESULTS}

We collected data on 100 patients admitted over the study period. One patient had incomplete outcome data and was excluded from further analyses. The 99 patients with complete outcome data, had a mean age of 6.5 years (SD 4.4), 69 males $(70 \%)$, an average duration of symptoms of 4.9 days (SD 3.7). There was no significant patterns in distribution by age or sex related to the clinical outcome (Table 1). Most patients were from a rural area outside Hawassa, $n=83$ (84\%), only $63(64 \%)$ had completed vaccinations, and 15 $(23 \%)$ had mild wasting and $10(15 \%)$ had moderate-severe wasting for their nutritional status. For their clinical presentation, $98(99 \%)$ had fever, $45(46 \%)$ presented with seizures, 36(36\%) presented with loss of consciousness, and 92 (94\%) had neck stiffness. Many of the patients, $n$ $=64(72.2 \%)$, had received antibiotics prior to admission with a mean duration of prior antibiotics of 3.8 days $(\mathrm{SD}=2.5)$.

Examining the question of whether CSF WBC count was associated with a poor outcome, we first conducted a bivariate analysis of the demographic, clinical and treatment variables collected (Table 1). No association was found between CSF WBC count and outcome.

Seventy-one subjects had a CSF WBC count and a record of antibiotic receipt prior to admission. Examining the CSF WBC count variable, the Shapiro-Wilk test was significant for CSF WBC count. Therefore, we used nonparametric tests to address this question. The CSF WBC count was higher and the percent neutrophils higher in those patients who had not received any antibiotics prior to admission (Table 2).

Table 1: Comparison of demographics, clinical characteristics and laboratory parameters by clinical outcome of the patients.

DOI: http://dx.doi.org/10.4314/ejhs.v27i6.3 


\begin{tabular}{|c|c|c|c|c|c|}
\hline & $\begin{array}{c}\text { Improved } \\
(n=75)\end{array}$ & $\begin{array}{c}\text { Discharged with } \\
\text { complication or against } \\
\text { advice }(n=8)\end{array}$ & Died $(n=16)$ & All $(n=99)$ & p-value \\
\hline \multicolumn{6}{|l|}{ Age } \\
\hline$<1$ year of age & $11(15 \%)$ & $1(12 \%)$ & $2(12 \%)$ & $14(14 \%)$ & \multirow{4}{*}{0.90} \\
\hline $1-5$ years of age & $23(31 \%)$ & $3(38 \%)$ & $6(38 \%)$ & $32(32 \%)$ & \\
\hline $5-10$ years of age & $25(33 \%)$ & $1(12 \%)$ & $5(31 \%)$ & $31(31 \%)$ & \\
\hline $10-18$ years of age & $16(21 \%)$ & $3(38 \%)$ & $3(19 \%)$ & $22(22 \%)$ & \\
\hline \multicolumn{6}{|l|}{ Sex } \\
\hline Male & $51(68 \%)$ & $6(75 \%)$ & $12(75 \%)$ & $69(70 \%)$ & \multirow[t]{2}{*}{0.81} \\
\hline Female & $24(32 \%)$ & $2(25 \%)$ & $4(25 \%)$ & $30(30 \%)$ & \\
\hline $\begin{array}{l}\text { Duration of symptoms, mean } \\
\text { (SD) }\end{array}$ & $4.3(3.4)$ & $7.1(4.6)$ & $6.9(3.9)$ & $4.9(3.7)$ & $<0.01$ \\
\hline \multicolumn{6}{|l|}{ Patient from: } \\
\hline Hawassa & $14(19 \%)$ & $0(0 \%)$ & $2(13 \%)$ & $16(16 \%)$ & \multirow[t]{2}{*}{0.45} \\
\hline Outside Hawassa & $61(81 \%)$ & $8(100 \%)$ & $14(87 \%)$ & $83(84 \%)$ & \\
\hline \multicolumn{6}{|l|}{ Seizures } \\
\hline Yes & $34(45 \%)$ & $3(38 \%)$ & $8(50 \%)$ & $45(46 \%)$ & \multirow[t]{2}{*}{0.83} \\
\hline No & $41(55 \%)$ & $5(62 \%)$ & $8(50 \%)$ & $54(54 \%)$ & \\
\hline \multicolumn{6}{|l|}{ LOC } \\
\hline Yes & $26(35 \%)$ & $0(0 \%)$ & $10(63 \%)$ & $36(36 \%)$ & \multirow[t]{2}{*}{$<0.01$} \\
\hline No & $49(65 \%)$ & $8(100 \%)$ & $6(37 \%)$ & $93(64 \%)$ & \\
\hline \multicolumn{6}{|l|}{ Neck stiffness $\ddagger$} \\
\hline Yes & $69(92 \%)$ & $8(100 \%)$ & $15(100 \%)$ & $92(94 \%)$ & \multirow[t]{2}{*}{1.0} \\
\hline No & $6(8 \%)$ & $0(0 \%)$ & $0(0 \%)$ & $6(6 \%)$ & \\
\hline \multicolumn{6}{|l|}{ Vaccinated } \\
\hline Yes, complete & $49(65 \%)$ & $4(50 \%)$ & $10(63 \%)$ & $63(64 \%)$ & \multirow[t]{2}{*}{0.77} \\
\hline Incomplete & $26(35 \%)$ & $4(50 \%)$ & $6(37 \%)$ & $36(36 \%)$ & \\
\hline \multicolumn{6}{|l|}{ Malnourishment status } \\
\hline Normal & $33(66 \%)$ & $3(50 \%)$ & $5(50 \%)$ & $41(62 \%)$ & \multirow[t]{3}{*}{0.14} \\
\hline Mild & $11(22 \%)$ & $2(33 \%)$ & $2(20 \%)$ & $15(23 \%)$ & \\
\hline Moderate to severe & $6(12 \%)$ & $1(17 \%)$ & $3(30 \%)$ & $10(15 \%)$ & \\
\hline \multicolumn{6}{|l|}{ TB contact } \\
\hline Yes & $3(4 \%)$ & $1(12 \%)$ & $0(0 \%)$ & $4(4 \%)$ & \multirow[t]{2}{*}{0.39} \\
\hline No & $72(96 \%)$ & $7(88 \%)$ & $16(100 \%)$ & $95(96 \%)$ & \\
\hline \multicolumn{6}{|l|}{ HIV } \\
\hline Negative & $48(64 \%)$ & $7(88 \%)$ & $12(75 \%)$ & $67(67 \%)$ & \multirow[t]{3}{*}{0.52} \\
\hline Positive & $1(1 \%)$ & $0(0 \%)$ & $0(0 \%)$ & $1(1 \%)$ & \\
\hline Unknown & $26(35 \%)$ & $1(12 \%)$ & $4(25 \%)$ & $31(31 \%)$ & \\
\hline \multicolumn{6}{|l|}{ Received prior antibiotics } \\
\hline Yes & $46(69 \%)$ & $6(100 \%)$ & $12(75 \%)$ & $64(72 \%)$ & \multirow[t]{2}{*}{0.35} \\
\hline No & $21(31 \%)$ & $0(0 \%)$ & $4(25 \%)$ & $25(28 \%)$ & \\
\hline $\begin{array}{l}\text { WBC count in thousands, } \\
\text { peripheral, median [IQR] }\end{array}$ & $12.9[9.0-17.7]$ & $12.5[9.7-14.7]$ & $\begin{array}{c}13.2[7.8- \\
19.9]\end{array}$ & $\begin{array}{c}13.0[9.0- \\
17.1]\end{array}$ & 0.99 \\
\hline $\begin{array}{l}\text { CSF WBC count, median } \\
\text { [IQR] }\end{array}$ & $537[0-5600]$ & $227[65-4160]$ & $432[216-454]$ & $432[0-4880]$ & 0.29 \\
\hline $\begin{array}{l}\text { CSF \% neutrophils, median } \\
{[\mathrm{IQR}]}\end{array}$ & $59[0-90]$ & $13[0-84$ & $63[32-75]$ & $59[0-90]$ & 0.67 \\
\hline CSF protein, median [IQR] & 109 [70-179] & $381[76-1300]$ & $100[91-171]$ & 109 [73-242] & 0.50 \\
\hline CSF glucose, median [IQR] & $39[12-62]$ & $44[34-46]$ & $16[13-147]$ & $39[12-61]$ & 0.41 \\
\hline
\end{tabular}

$\mathrm{IQR}=$ interquartile range; $\mathrm{SD}=$ standard deviation; $\mathrm{LOC}=$ loss of consciousness; $\mathrm{CSF}=$ cerebrospinal fluid; WBC $=$ white blood cell; $\uparrow$ categories have less than 99 subjects due to missing data

DOI: http://dx.doi.org/10.4314/ejhs.v27i6.3 
Table 2: Cerebrospinal fluid white blood cell count analyzed by receipt of prior antibiotics, comparison by non-parametric Mann Whitney U-test, presented as median with $25^{\text {th }}-75^{\text {th }}$ percentiles

\begin{tabular}{lccc}
\hline & $\begin{array}{c}\text { Prior antibiotics } \\
(\mathbf{n = 5 2})\end{array}$ & $\begin{array}{c}\text { No prior antibiotics } \\
(\mathbf{n = 1 9 )}\end{array}$ & p-value \\
\hline $\begin{array}{l}\text { CSF WBC count median } \\
\text { [IQR] }\end{array}$ & $170[3-750]$ & $1810[0-9230]$ & 0.06 \\
$\begin{array}{l}\text { CSF WBC \% neutrophils } \\
\text { median [IQR] }\end{array}$ & $40[1-74]$ & $90[0-94]$ & 0.02 \\
\hline
\end{tabular}

$\mathrm{CSF}=$ cerebrospinal fluid; IQR $=$ interquartile range; $\mathrm{WBC}=$ white blood cell

The analysis of antibiotic type administered in the hospital with outcome demonstrated that a higher proportion of patients who received ceftriaxone died (Table 3). We then explored whether there might be an association between type of antibiotic administered in the hospital and any receipt of antibiotics prior to hospitalization. Indeed, nearly all of the patients who received ceftriaxone had received antibiotics of some kind prior to being hospitalized, and the majority of the subjects who received chloramphenicol and penicillin had not received prior antibiotic therapy (Table 4). Of those who had been treated with antibiotics prior to arrival, there was no difference in survival by type of antibiotic $(p=0.45)$ or by receipt of dexamethasone $(p=0.34)$. Examinination of only those who did not receive antibiotics prior to presentation proved that there was was a significant association between dexamethasone and survival ( $\mathrm{p}=0.02$ Fisher's exact test), and no difference in outcome based on antibiotic administered in hospital $(\mathrm{p}=0.42)$.

Finally, our multivariable analysis using forward, step-wise logistic regression with the binomial outcome of survival demonstrated a significant associations between death and malnutrition $(\mathrm{OR}=2.8,95 \% \mathrm{CI}: 1.1,7.7)$, duration of symptoms prior to admission $(\mathrm{OR}=$ 1.4, 95\% CI: 1.1, 1.9) and an apparent negative association between loss of consciousness (OR = $0.02,95 \%$ CI: $0.01,0.2$ ) and survival.

Table 3: Comparison of clinical outcomes by antibiotic administered during hospitalization, Fisher's exact test used for comparisons .

\begin{tabular}{|c|c|c|c|c|c|}
\hline & $\begin{array}{l}\text { Improved } \\
(n=74)\end{array}$ & $\begin{array}{l}\text { Discharged with } \\
\text { complication or } \\
\text { against advice }(n=8)\end{array}$ & Died $(n=16)$ & All $(n=98)$ & $\begin{array}{l}p- \\
\text { value }\end{array}$ \\
\hline \multicolumn{6}{|l|}{ Antibiotic } \\
\hline Ceftriaxone & $34(46 \%)$ & $3(38 \%)$ & $10(63 \%)$ & $47(48 \%)$ & 0.07 \\
\hline $\mathrm{CAF}+\mathrm{PCN}$ & $31(42 \%)$ & $1(12 \%)$ & $4(25 \%)$ & $36(37 \%)$ & \\
\hline $\begin{array}{l}\text { Miscellaneous } \\
\text { combinations }\end{array}$ & $9(12 \%)$ & $4(50 \%)$ & $2(12 \%)$ & $15(15 \%)$ & \\
\hline \multicolumn{6}{|l|}{ Received dexamethasone } \\
\hline Yes & $48(65 \%)$ & $5(62 \%)$ & $5(31 \%)$ & $58(59 \%)$ & 0.05 \\
\hline No & $26(35 \%)$ & $3(38 \%)$ & $11(69 \%)$ & $40(41 \%)$ & \\
\hline
\end{tabular}

DOI: http://dx.doi.org/10.4314/ejhs.v27i6.3 
Table 4: Association between children who received antibiotics prior to admission and the type of antibiotic and receipt of dexamethasone administered in the hospital.

\begin{tabular}{lllll}
\hline & $\begin{array}{l}\text { Prior antibiotics } \\
(\mathbf{n = 6 3 )}\end{array}$ & $\begin{array}{l}\text { No prior antibiotics } \\
(\mathbf{n = 2 5})\end{array}$ & All (n=88) & p-value \\
\hline Antibiotic in hospital & & & & $<0.001$ \\
Ceftriaxone & $39(62 \%)$ & $3(12 \%)$ & $42(48 \%)$ & \\
CAF + PCN & $9(14 \%)$ & $22(88 \%)$ & $31(35 \%)$ & \\
Miscellaneous combinations & $15(24 \%)$ & $0(0 \%)$ & $15(17 \%)$ & \\
$\begin{array}{l}\text { Received dexamethasone } \\
\text { Yes }\end{array}$ & $25(39 \%)$ & & $48(54 \%)$ & \\
No & $39(61 \%$ & $23(92 \%)$ & $41(46 \%)$ & \\
\hline CAF = chloramphenicol; PCN $=0.001$ \\
metronidazole, vancomycin, gentamicin, cloxacillin and ceftazidime
\end{tabular}

\section{DISCUSSION}

This study shows the challenge of diagnosing meningitis definitively in a resource-limited setting without reliable access to cultures or gram stain. Clinicians face significant difficulties in treatment with long periods of illness and prior oral antibiotic exposure before presenting to care at an appropriate facility.

We asked three simple questions that practitioners face on a daily basis. Our data suggest that the pattern of CSF pleocytosis among patients treated with antibiotics prior to lumbar puncture is different from those who had not received antibiotics with higher CSF WBC counts and higher neutrophil percentages in those who had not received antibiotics. However, both groups had CSF WBC counts well above normative clinical values, and so the clinical significance of this difference is limited. Prior work done in the U.S. found no difference in CSF WBC counts between those pre-treated with antibiotics and who were not not pre-treated (10). One potential explanation for the difference in findings is the length of pre-treatment. While not a formal measure in our study, clinical experience informs us that many patients may go days on antibiotic therapy in this context whereas in the U.S. the comparisons were between 12-24 hours of antibiotic pretreatment. Another study done in India also did not find a difference in CSF WBC count between pretreatment and no pretreatment, with the primary difference between that study and this one being their focus on children $<2$ years of age (14).

The implications of using broad clinical criteria for acute meningitis syndrome include overtreatment of children who have viral or aseptic meningitis and potentially inducing antibiotic resistance. Other studies have highlighted the poor performance of clinical predictors of bacterial meningitis $(6,9,14)$, or they have found positive clinical predictors of only severe presentations or findings, e.g. loss of consciousness (15).

We did not find a relationship between level of CSF pleocytosis and outcome in children clinically diagnosed to have acute meningitis. We found that chloramphenicol and penicillin were associated with a lower mortality than ceftriaxone. However, this association is most likely confounded by both prior antibiotic use and longer duration of symptoms prior to presentation. Indeed, this apparent difference in antibiotic effectiveness is likely the result of partial treatment of meningitis in those patients exposed to prior antibiotics and not the empiric antibiotic regimen used in the hospital. One of the clear areas for improvement and standardization lies in the choice of antibiotics in these patients.

High levels of prior antibiotic use have been found in other developing world analyses of acute meningitis syndrome (14). Addressing inappropriate antibiotic use in the developing world has several challenges. Education for both first level providers and community leaders on 
signs and symptoms that differentiate meningitis from other febrile illnesses should continue. One recent study used qualitative methods to determine that malaria was often confused with meningitis, and that this was the reason for the delay in care (16).

Previously, dexamethasone was not shown to overall reduce mortality in pediatric bacterial meningitis, and this includes results from studies done in low-income countries (17). There has been some demonstrated benefit on mortality from certain species (Streptococcus pneumoniae) and significant associations between corticosteroids and neurologic sequelae including hearing loss (17). We do not have species-specific data, and the associations between survival and dexamethasone in subgroups of this study do not provide convincing evidence. However, our findings do warrant further investigation into the use of dexamethasone in this population. The need for better implementation of complete vaccinations cannot be understated given that nearly one-third of the patients in this study were incompletely vaccinated, and the vaccines against the major bacterial causes of meningitis are highly effective (18).

The limitations of this study reflect the limitations of the local practice. The diagnosis of meningitis was initially aclinical diagnosis alongside CSF findings without the ability to confirm through bacterial culture and limited antigen testing. Therefore, it is impossible to differentiate cases of tuberculous meningitis or aseptic meningitis in this study. Furthermore, for the analysis of the CSF, we did not have a comparison group of children without suspicion for acute meningitis such as those with elevated intracranial pressure, etc. Finally, there is some risk of selection bias in that the cases were entered manually by the staff when a case was suspected. It is therefore possible that more severe presentations are over-represented in this series. On the other hand, unstable patients in whom a CSF sample could not be obtained were excluded. The limitation of incomplete data acquisition is also present as some patients had incomplete data on their receipt of antibiotics prior to presentation or for their CSF parameters such as WBC count, despite it being collected.

The challenge of resource limitations is not likely to go away any time soon for much of the world, but we do have the ability to track clinical outcomes and use comparative effectiveness to improve care, either by definitely answering questions or identifying best next steps forward. This study helps delineate the remaining questions and how to address them for the practical management of acute meningitis where the majority of the burden of the disease occurs.

In conclusion, while the CSF WBC count may be lower in patients pre-treated with antibiotics, it is not clinically significant. There was no association in this study between level of CSF pleocytosis and outcomes for children with meningitis. While different antibiotic regimens were associated with differential survival, this association was confounded by the receipt of prior antibiotic therapy and length of illness prior to presentation. The next step will be conducting clinical studies comparing empiric antibiotic regimens between groups of patients and evaluating the role of dexamethasone. Specifically, stratification by receipt of prior antibiotics and randomization within those groups to different empiric regimens in a clinical trial is arguably the best next step forward. Further analyses of clinical data in this context will be challenged by the significant effect of the confounders of prior antibiotic exposure and length of illness prior to presentation.

\section{REFERENCES}

1. Ramakrishnan M, Ulland AJ, Steinhardt LC, Moïsi JC, Were F, Levine OS. Sequelae due to bacterial meningitis among African children: a systematic literature review. BMC Med. 2009;7:47.

2. Jusot J-F, Tohon Z, Yazi AA, Collard J-M. Significant sequelae after bacterial meningitis in Niger: a cohort study. BMC Infect Dis. 2013;13:228.

3. McCormick DW, Wilson ML, Mankhambo L, Phiri A, Chimalizeni Y, Kawaza K, et al. Risk factors for death and severe sequelae in Malawian children with bacterial meningitis,

DOI: http://dx.doi.org/10.4314/ejhs.v27i6.3 
1997-2010. Pediatr Infect Dis J. 2013;32(2):e54-61.

4. Cohn A, MacNeil J. The Changing Epidemiology of Meningococcal Disease. Infect Dis Clin North Am. 2015;29(4):667-77.

5. Sadarangani M, Scheifele DW, Halperin SA, Vaudry W, Le Saux N, Tsang R, et al. Outcomes of Invasive Meningococcal Disease in Adults and Children in Canada Between 2002 and 2011: A Prospective Cohort Study. Clin Infect Dis. 2015;60(8):e27-35.

6. Águeda S, Campos T, Maia A. Prediction of bacterial meningitis based on cerebrospinal fluid pleocytosis in children. Braz J Infect Dis. 2013;17(4):401-4.

7. Scarborough M, Thwaites GE. The diagnosis and management of acute bacterial meningitis in resource-poor settings. Lancet Neurol. 2008 Jul;7(7):637-48.

8. Nigrovic LE, Malley R, Kuppermann N. Metaanalysis of bacterial meningitis score validation studies. Arch Dis Child. 2012;97(9):799-805.

9. Kulik DM, Uleryk EM, Maguire JL. Does this child have bacterial meningitis? A systematic review of clinical prediction rules for children with suspected bacterial meningitis. $J$ Emerg Med. 2013;45(4):508-19.

10. Nigrovic LE, Malley R, Macias CG, Kanegaye JT, Moro-Sutherland DM, Schremmer RD, et al. Effect of antibiotic pretreatment on cerebrospinal fluid profiles of children with bacterial meningitis. Pediatrics. 2008;122(4):726-30.

11. Kanegaye JT, Soliemanzadeh P, Bradley JS. Lumbar puncture in pediatric bacterial meningitis: defining the time interval for recovery of cerebrospinal fluid pathogens after parenteral antibiotic pretreatment. Pediatrics. 2001;108(5):1169-74.

12. Standard Treatment Guidelines for District Hospital - Ethiopia. Drug Administration and Control Authority. 2004. Available from: http://collections.infocollections.org/whocount $\mathrm{ry} / \mathrm{en} / \mathrm{d} / \mathrm{Js} 6852 \mathrm{e} / 5.12 \mathrm{html}$

13. WHO Child Growth Standards and the Identification of Severe Acute Malnutrition in Infants and Children. WHO Child Growth
Standards and the Identification of Severe Acute Malnutrition in Infants and Children: A Joint Statement by the World Health Organization and the United Nations Children's Fund. World Health Organization; 2009.

14. Fitzwater SP, Ramachandran P, Nedunchelian K, Kahn G, Santosham M, Chandran A. Bacterial meningitis in children $<2$ years of age in a tertiary care hospital in South India: an assessment of clinical and laboratory features. J Pediatr. 2013;163:S32-7.

15. Weber MW, Herman J, Jaffar S, Usen S, Oparaugo A, Omosigho $\mathrm{C}$, et al. Clinical predictors of bacterial meningitis in infants and young children in The Gambia. Trop Med Int Health. 2002 Sep;7(9):722-31.

16. Desmond NA, Nyirenda D, Dube Q, Mallewa M, Molyneux E, Lalloo DG, et al. Recognising and treatment seeking for acute bacterial meningitis in adults and children in resource-poor settings: a qualitative study. PLoS One. 2013;8(7):e68163.

17. Brouwer MC, McIntyre P, Prasad K, van de Beek D. Corticosteroids for acute bacterial meningitis. Cochrane database Syst Rev. 2013;6:CD004405.

18. Davis S, Feikin D, Johnson HL. The effect of Haemophilus influenzae type $B$ and pneumococcal conjugate vaccines on childhood meningitis mortality: a systematic review. BMC Public Health. 2013;13(Suppl 3):S21. 